\title{
Met de voeten in de klei
}

\author{
Citation for published version (APA):
}

Schaalma, H. (2007). Met de voeten in de klei. Maastricht University. https://doi.org/10.26481/spe.20070722hs

Document status and date:

Published: 22/07/2007

DOI:

10.26481/spe.20070722hs

Document Version:

Publisher's PDF, also known as Version of record

\section{Please check the document version of this publication:}

- A submitted manuscript is the version of the article upon submission and before peer-review. There can be important differences between the submitted version and the official published version of record.

People interested in the research are advised to contact the author for the final version of the publication, or visit the DOI to the publisher's website.

- The final author version and the galley proof are versions of the publication after peer review.

- The final published version features the final layout of the paper including the volume, issue and page numbers.

Link to publication

\footnotetext{
General rights rights.

- You may freely distribute the URL identifying the publication in the public portal. please follow below link for the End User Agreement:

www.umlib.nl/taverne-license

Take down policy

If you believe that this document breaches copyright please contact us at:

repository@maastrichtuniversity.nl

providing details and we will investigate your claim.
}

Copyright and moral rights for the publications made accessible in the public portal are retained by the authors and/or other copyright owners and it is a condition of accessing publications that users recognise and abide by the legal requirements associated with these

- Users may download and print one copy of any publication from the public portal for the purpose of private study or research.

- You may not further distribute the material or use it for any profit-making activity or commercial gain

If the publication is distributed under the terms of Article $25 \mathrm{fa}$ of the Dutch Copyright Act, indicated by the "Taverne" license above, 
Met de voeten in de klei 


\section{Colofon}

Basisontwerp en realisatie: Océ Business Services, Universiteit Maastricht.

Afbeelding omslag: Peter Oosting

ISBN: $978-90-5681-259-1$

NUR 770

Alle rechten voorbehouden. Niets uit deze uitgave mag worden verveelvoudigd, opgeslagen in een geautomatiseerd gegevensbestand of openbaar gemaakt, zonder voorafgaande schriftelijke toestemming van de auteur of uitgever. 


\section{Met de voeten in de klei}

Rede

In vrije vorm uitgesproken bij de aanvaarding van het ambt van bijzonder hoogleraar Aidspreventie aan de Faculteit der Psychologie van de Universiteit Maastricht

dr. Herman Schaalma

vrijdag 22 juni 2007

U

Universiteit Maastricht 

Mijnheer de Rector, beste collega's, familie en vrienden,

\section{Met de voeten in de klei}

\section{Inleiding}

Zo'n 17 jaar geleden verhuisde ik van Groningen naar Maastricht. Mijn toenmalige vrienden vonden dit maar een merkwaardige stap, en bovenal erg moedig. Van het hoge land 'woar de zee broest en de wind hoelt, woar 't soest aan diek en wad', naar het heuvelland waar een nachtegaaltje zingt in bronsgroen eikenhout. Dat kon toch haast niet goed gaan; dat moest mij wel zwaar vallen.

Hoe zou ik - geboren en getogen in een deel van Nederland waar de mensen zich laten schetsen door de woorden 'stug', 'bot', 'degelijk' en 'met de voeten in de klei' - ooit kunnen aarden in de gezellige, gastvrije, frivole, Bourgondische feestcultuur van Maastricht waar men met een 'kump good' mentaliteit graag 'op chique' is.

Nu sta ik hier niet om $u$ te vertellen dat het leven in Maastricht mij prima bevalt; dat ik hier na al die jaren sta, zegt wat dat betreft genoeg. Ik sta hier ook niet om $u$ uit te leggen dat de volksliederen van beide provincies blijk geven van mentaliteitsverschillen tussen Groningers en Limburgers, en dat echte Maastrichtenaren, echte Sjengen, maar weinig ophebben met bronsgroen eikenhout. Waar ik het vanmiddag wel over wil hebben, zijn kwesties die alle met mentaliteitsverschillen te maken hebben. Ik ga het hebben over cultuursensitieve preventie van aids en andere seksueel overdraagbare aandoeningen, soa's - het onderwerp van de bijzondere leerstoel die ik vanmiddag aanvaard. Hoe kunnen we preventieprogramma's maken die zijn toegesneden op de cultuur van de mensen waarvoor zij zijn bedoeld?

Ik zal dit doen vanuit het perspectief van theory- and evidence-based preventie, wetenschappelijk onderbouwde preventie. In het Nederlands ook wel planmatige voorlichting genoemd (Kok, Schaalma \& Brug, 2007). Voor het gemak zal ik vanmiddag de term planmatige preventie aanhouden. Binnen het perspectief van planmatige preventie zal ik een nadruk leggen op de rol van de psychologie. Gaandeweg hoop ik u een idee geven van wat een Groningse psycholoog uit Maastricht denkt te kunnen bijdragen aan de aids/soa preventie aan migrantengroepen in Nederland, en aan de aids/soa preventie in ontwikkelingslanden. Voordat 
ik hier aan begin, wil eerst mogelijke misverstanden uit de weg ruimen over het de begrippen preventie, cultuur en cultuursensitieve preventie.

\section{Preventie}

Wanneer ik het vanmiddag heb over preventie, en over de preventie van aids/soa in het bijzonder, dan doel ik niet alleen op tv-spotjes, affiches en voorlichtingsfoldertjes. Als ik het heb over preventie, dan heb ik het over alle activiteiten die we kunnen ondernemen om te stimuleren dat mensen zich op vrijwillige basis 'gezonder' en 'veiliger' gaan gedragen (Green \& Kreuter, 2005). Preventie is meer dan mensen informatie geven over ziekte en gezondheidsrisico's; preventie is meer dan informeren en bangmakerij. Met preventie doel ik ook op lesprogramma's, theater, straathoekwerk, trainingen, televisieseries of shows, internetprogramma's en misschien zelfs wel op carnavalsliedjes als 'Dink droan. Dink drum'. Bij preventie moet u ook niet alleen aan voorlichting denken, maar ook aan voorzieningen en regel- en wetgeving, zoals het verstrekken van schone spuiten aan druggebruikers, toegankelijke testvoorzieningen en wetgeving om discriminatie van mensen met hiv tegen te gaan.

Als ik het over preventie heb, dan heb ik het ook niet alleen over activiteiten die we kunnen ondernemen om te voorkómen dat mensen met hiv of een andere soa geïnfecteerd raken: we noemen dat primaire preventie. Met preventie doel ik ook op het tijdig opsporen van mensen met een infectie: vroege opsporing ofwel secundaire preventie. Preventie is dus ook mensen motiveren om zich tijdig of regelmatig op hiv of andere soa te laten testen. En als ik het heb over preventie, dan bedoel ik ook de zorg voor mensen met hiv: tertiaire preventie. $U$ kunt hierbij denken aan activiteiten die bevorderen dat mensen goed en volhardend omgaan met aidsremmers.

\section{Cultuursensitieve preventie}

Als we het in preventieland ergens over eens zijn, dan is het wel dat preventieprogramma's cultuursensitief moeten zijn om verschil te kunnen maken. Dit idee is zo vanzelfsprekend, dat maar weinigen zich hebben gebogen over de vraag wat we hier nu eigenlijk onder moeten verstaan. Wat is cultuursensitief? Wanneer is preventie cultuursensitief? Hoe maak je preventie cultuursensitief? En wat verstaan we eigenlijk onder cultuur? 
Cultuur is een rare, een lastige term. Het is een woord dat we voortdurend in de mond nemen zonder dat precies duidelijk is waar we het eigenlijk over hebben. Voor het begrip cultuur zijn in de loop der jaren talloze definities gegeven (zie o.a. Groseschl \& Doherty, 2000), en het lijkt inherent aan het begrip dat het gebruik en de interpretatie ervan eindeloze discussies met zich meebrengt. Cultuur is wat dat betreft net als kunst en de beste opstelling van Oranje een dankbaar onderwerp voor kroegenpraat, verjaardagsfeestjes en academische recepties.

Omdat ik u niet wil vervelen met een wetenschapstheoretische discussie over het begrip cultuur, wil ik voor vanmiddag een gangbare definitie aanhouden. Cultuur is het totaal van ideeën, opvattingen, waarden en gewoonten die ons over generaties heen met de paplepel is ingegoten; cultuur staat voor patronen van denken, voelen en doen die ons in de loop van ons leven zijn aangeleerd, en die van generatie op generatie worden overgedragen (Hofstede \& Hofstede, 2007).

Met deze definitie loop ik onder anderen in de pas met Geert Hofstede, van 1985 tot 1993 hoogleraar bij onze universiteit. Hofstede, internationaal gezien de meest geciteerde Nederlandse econoom, geldt wereldwijd als de grondlegger van vergelijkend intercultureel onderzoek en hij is sinds enige tijd door de Universiteit Maastricht geëerd met de instelling van de Geert Hofstede leerstoel voor Culturele Diversiteit. Ere die eer toekomt, maar dit terzijde.

Hofstede omschrijft cultuur als de 'collectieve mentale programmering die de leden van één groep ... mensen onderscheidt van die van andere' (Hofstede \& Hofstede, 2007, p. 19). Cultuur als deel van onze software; cultuurverschil als incompatible software. Volgens Hofstede moeten we cultuur niet alleen als software zien, maar ook als een ui. Aan de buitenkant, de schil van de ui, manifesteert cultuur zich zoals we dat kennen als we op vakantie zijn in het buitenland. Daar verbazen we ons over politieagenten die hand in hand surveilleren, over ontmoetingsrituelen en onderhandelingsstrategieën en over bussen die pas gaan rijden als zij vol zitten. Aan de buitenkant van de ui vinden we de oppervlakkige uitingen van cultuur. De kern van de cultuur wordt gevormd door waarden, door 'een collectieve neiging om bepaalde zaken te verkiezen boven andere' (Hofstede \& Hofstede, 2007, p. 23), door impliciete regels die meebepalen of we iets goed, veilig, fatsoenlijk, onnatuurlijk, smerig of immoreel vinden. Hierbij kunt u denken aan de mate waarin we waarde hechten aan gelijkheid of aan machts- en statusverschillen. $U$ kunt ook denken aan de mate waarin we het individuele belang ondergeschikt achten aan het groepsbelang, bijvoorbeeld het belang van de familie. 
Ook kunt $u$ denken aan het belang dat we hechten aan presteren en geld verdienen, of juist aan goede relaties en innerlijke zelfontplooiing. Met betrekking tot seksualiteit kunt $u$ denken aan waarden die te maken hebben met seksuele voorkeur, sekserollen of man-vrouw verschillen, seks voor het huwelijk en met taboes rond masturbatie, praten over seks en seks om de seks.

Preventieprogramma's zijn cultuursensitief als zij zijn afgestemd op de volledige ui. Preventie is cultuursensitief als het is afgestemd op taal, kleur, vorm, en de context waarin mensen leven, en op de culturele waarden en normen van een bepaalde groep (Resnicow, Baranowski, Ahluwalia \& Braithwaite, 1999).

De vraag is nu hoe we dit handen en voeten kunnen geven. Hoe breng je cultuur in kaart, hoe bepaal je cultuur. En hoe stem je preventieprogramma's af op cultuur? En de vraag die mijzelf intrigeert: hoe kunnen we dit op de een of andere manier wetenschappelijk onderbouwen. Wat hebben we aan wetenschap als we cultuursensitieve preventieprogramma's willen ontwikkelen?

De afstemming van preventie op de schil van de culturele ui, lijkt nog wel te doen. We geven voorlichting in de eigen taal, gebruiken vormen en kleuren die mensen leuk vinden en we spreken ze aan als specifieke groep (Kreuter, Lukwago, Bucoltz, Clark \& Sanders-Thompson, 2002; Wilson \& Miller, 2003). Het programma Voorlichting in Eigen Taal en Cultuur is hiervan een mooi voorbeeld. Als we Antillianen willen voorlichten, dan laten we dat doen door Antilliaanse voorlichters. En die voorlichters hebben het dan vooral over zaken die van belang zijn voor de Antilliaanse gemeenschap. Het afstemmen van preventie op het hart van de culturele uit heeft echter heel wat meer voeten in aarde. Het valt doorgaans al niet mee om onze eigen ui te pellen; het schillen van de ui van een ander kost meestal veel bloed, zweet en vooral veel tranen.

In de loop der jaren zijn er verschillende procedures voorgesteld om preventie cultuursensitief te maken (Resnicow et al., 1999; Airhihenbuwa, 1995; 2005). Deze procedures bestaan hoofdzakelijk uit twee activiteiten:

1) kwalitatief vooronderzoek, en

2) het uittesten of pretesten van programma's onder de doelgroep. Een serie groepsdiscussies moet inzicht geven in samenhangen tussen probleem, oorzaken en culturele context. Pretest-onderzoek moet vervolgens uitwijzen of we er in zijn geslaagd om iets te maken dat aansluit bij de normen, waarden en gewoontes van onze doelgroep (Resnicow et al., 1999). 
Los van het feit dat dergelijke procedures ongetwijfeld bijdragen tot een afstemming van programma's op de doelgroep, schieten ze te kort voor een wetenschappelijke onderbouwing van het ontwikkelen van cultuursensitieve preventie. Ze geven te weinig richtlijnen voor programmaontwikkelaars die cultuur willen betrekken bij alle fasen van programmaontwikkeling (Bernal, Bonilla \& Bellido, 1995); programmamakers die culturele context willen betrekken bij het definiëren van programmadoelen, het identificeren van interventiestrategieën en bij de implementatie en evaluatie van preventieprogramma's. Planmatige preventie biedt deze programmaontwikkelaars volgens mij een bruikbaar raamwerk.

Voordat ik $u$ wat ga vertellen over planmatige preventie wil ik eerst even een kanttekening plaatsen. Het is opvallend dat het in vrijwel alle wetenschappelijke literatuur over cultuursensitieve programma's gaat over minderheden en etnische afkomst. Het gaat vrijwel altijd over preventie in Afrika of Latijns Amerika, over migranten, etnische minderheden zoals latinos en negers - of zo u wilt: African Americans. Of het gaat over groepen als druggebruikers en mannen die seks hebben met andere mannen, al dan niet gekoppeld aan etnische afkomst. Ik doe daar vandaag zelf aan mee, dus het is een beetje de pot verwijt de ketel. Maar het suggereert dat cultuur in andere gevallen geen issue is. Dat cultuur en culturele sensitiviteit niet, of in sterk mindere mate, van belang is als programmaontwikkelaars van een jaar of 50 seksuele voorlichtingsprogramma's ontwerpen voor vmbo-scholieren van een jaar of 14 . Ik vind dit onjuist. Ik vind dat cultuur, of misschien moeten we hier spreken van subcultuur, altijd van belang moet zijn bij de ontwikkeling en implementatie van preventieprogramma's, en niet alleen als er sprake is van taalverschillen of een exotisch kleurtje.

\section{Planmatige Preventie}

Met theory and evidence-based preventie, of planmatige aidspreventie, bedoelen we een activiteit of proces waarin we proberen om onze programma's te baseren op uitkomsten van empirisch onderzoek, en op theorieën over gedrag en gedragsverandering (Green \& Kreuter, 2005; Bartholomew, Parcel, Kok \& Gottlieb, 2006; Kok et al., 2007). Waarom? Omdat wetenschappelijk onderbouwde preventie een grotere kans van slagen heeft.

Planmatige preventie is niet eenvoudig; het is een vak apart dat een multidisciplinaire aanpak vereist. Epidemiologie, sociologie, antropolo- 
gie, psychologie, voorlichtingskunde zijn een aantal wetenschappelijke disciplines die waardevol kunnen bijdragen aan de totstandkoming van preventieprogramma's.

\begin{tabular}{|c|c|c|}
\hline \multirow{6}{*}{ Evaluatie } & $\begin{array}{l}\text { Stap } 1 \\
\text { Needs Assessment }\end{array}$ & $\begin{array}{l}\text { Taak } 1.1 \text { Identificeer risicogroepen, kwaliteit van leven en } \\
\text { gezondheidsproblemen. } \\
\text { Taak } 1.2 \text { Identificeer gedrags- en omgevingsfactoren } \\
\text { Taak } 1.3 \text { Identificeer determinanten } \\
\text { Taak } 1.4 \text { Kies preventiedoelen }\end{array}$ \\
\hline & $\begin{array}{l}\text { Stap } 2 \\
\text { Veranderingsdoelen }\end{array}$ & $\begin{array}{l}\text { Taak 2.1 Kies specifieke gedragsdoelen } \\
\text { Taak 2.2 Kies belangrijke, veranderbare determinanten } \\
\text { Taak 2.3 Kies (sub)doelgroepen. } \\
\text { Taak 2.4 Maak een matrix van specifieke veranderingsdoelen }\end{array}$ \\
\hline & $\begin{array}{l}\text { Stap } 3 \\
\text { Theoretische methodieken } \\
\text { en praktische technieken }\end{array}$ & $\begin{array}{l}\text { Taak } 3.1 \text { Bedenk theoretische methodieken bij de veranderingsdoelen } \\
\text { Taak 3.2 Leid methodieken af uit de theorie en de literatuur } \\
\text { Taak 3.3 Vertaal de methodieken in praktische voorlichtingstechnieken }\end{array}$ \\
\hline & $\begin{array}{l}\text { Stap } 4 \\
\text { Programmaontwerp } \\
\text { en productie }\end{array}$ & $\begin{array}{l}\text { Taak 4.1 Combineer de verschillende technieken in één plan } \\
\text { Taak 4.2 Ontwerp de voorlichtingsmaterialen } \\
\text { Taak 4.3 Test de materialen uit bij de doelgroep en produceer } \\
\text { de materialen. }\end{array}$ \\
\hline & $\begin{array}{l}\text { Stap } 5 \\
\text { Plan programma-invoering } \\
\text { en -gebruik }\end{array}$ & $\begin{array}{l}\text { Taak 5.1 Formeer een linkage groep } \\
\text { Taak 5.1 Kies implementatiedoelen } \\
\text { Taak 5.3 Identificeer determinanten } \\
\text { Taak 5.4 Maak een matrix van specifieke implementatiedoelen } \\
\text { Taak 5.5 Schrijf implementatieplan }\end{array}$ \\
\hline & $\begin{array}{l}\text { Stap } 6 \\
\text { Plan programma evaluatie }\end{array}$ & $\begin{array}{l}\text { Taak 6.1 Ontwikkel een evaluatiemodel } \\
\text { Taak 6.2 Ontwikkel vragen voor effect en proces evaluatie } \\
\text { Taak 6.3 Specificeer effectindicatoren en -maten } \\
\text { Taak 6.4 Specificeer een evaluatiedesign } \\
\text { Taak 6.5 Schrijf een evaluatieplan }\end{array}$ \\
\hline
\end{tabular}


Om het complexe ontwikkelingsproces van planmatige preventie transparant en inzichtelijk te maken is door Bartholomew, Parcel, Kok en Gottlieb (2006) een systematiek, een protocol, ontwikkeld dat programmaontwikkelaars concrete richtlijnen geeft voor het toepassen van onderzoeksresultaten en theorie: Intervention Mapping.

Intervention Mapping beschrijft het ontwikkelingsproces van preventieprogramma's in zes fasen of stappen. De eerste fase is gericht op een grondige analyse van gezondheidsproblemen, oorzaken en risicogroepen. De uitkomsten van deze analyses, ook wel needs assessment genoemd, zijn de empirische basis voor de tweede fase van het proces waarin specifieke preventiedoelen worden gedefinieerd. De derde fase is gericht op het uitwerken van op wetenschappelijke theorieën gebaseerde preventieactiviteiten en materialen. In de vierde fase begint het echte werk pas echt. In deze fase worden losse activiteiten en materialen gecombineerd tot een samenhangend programma, en worden materialen geproduceerd en uitgetest. De tweede laatste fasen van Intervention Mapping zijn gericht op het plannen en ontwikkelen van een strategie om het programma uit te voeren, en op het plannen van een zorgvuldige evaluatie.

Programmaontwikkelaars die met Intervention Mapping werken worden voortdurend uitgedaagd om een wetenschappelijke onderbouwing te geven voor alle beslissingen die zij gaandeweg het ontwikkelingsproces nemen. Het protocol vraagt om een verantwoording van programmadoelen: wat wil je precies veranderen, bij wie, waarom wil je dit veranderen en niet iets anders, en wat verwacht je dat een dergelijke verandering zal opleveren. Intervention Mapping vraag ook om een verantwoording van preventieactiviteiten: welke activiteiten wil je ondernemen, waarom deze activiteit en niet iets anders, denk je dat jouw activiteit de beoogde resultaten zal hebben, en zo ja, waarom dan wel.

Voor elke ontwikkelingsfase biedt Intervention Mapping hulpmiddelen in de vorm van specifieke taken die programmamakers moeten uitvoeren, procedures die zij hierbij kunnen volgen en werkdocumenten die zij hierbij kunnen gebruiken. Door het gebruik van deze werkdocumenten resulteert Intervention Mapping uiteindelijk in een soort bouwtekening of plattegrond van een preventieprogramma. Een bouwtekening waarin op een overzichtelijke manier wordt beschreven welke beslissingen zijn genomen, op welke gronden beslissingen zijn genomen, welke consequenties gemaakte keuzes hebben, en op welke gronden gemaakte keuzes eventueel zijn heroverwogen. 
Een dergelijke gedetailleerde programmabeschrijving is erg belangrijk. Zij maakt het voor anderen mogelijk om het programma na bouwen. Dit is essentieel voor preventie als wetenschap - zonder een gedetailleerde programmabeschrijving kunnen we immers niets repliceren. Maar zorgvuldige beschrijvingen van programma's en van hoe zij zijn ontwikkeld, zijn ook belangrijk voor de preventiepraktijk. Goede programmabeschrijvingen voorkomen dat er voortdurend kennis over preventieprogramma's weglekt; zij voorkomen dat preventiewerkers voortdurend het wiel weer opnieuw moeten uitvinden.

Naast het systematisch toepassen van wetenschap, staat samenwerking in Intervention Mapping centraal. Programmaontwikkeling vereist een voortdurende dialoog tussen wetenschappers en preventiewerkers aan de ene kant, en de mensen waarvoor de preventie is bedoeld en allerhande belanghebbenden aan de andere kant. Planmatige preventie is een activiteit waarin wetenschappers en preventiewerkers in nauwe samenwerking met doelgroepen en belanghebbenden nadenken over problemen en oorzaken, en over mogelijkheden voor oplossingen. Een preventieprogramma voor het onderwijs maak je niet zonder een actieve inbreng van scholieren en docenten (Schaalma \& Kok, 2006). Een preventieprogramma voor Surinaamse en Antilliaanse vrouwen verzin je niet achter je bureau (Bertens, Schaalma \& Van den Borne, 2004). Planmatige preventie is als zodanig geen academische exercitie; planmatige preventie is preventie met de voeten in de klei.

Wat heeft deze systematiek ons nu te bieden voor het maken van cultuursensitieve preventieprogramma's als het gaat om het cultuursensitief maken van interventies? Wanneer en op wat voor gronden besluiten we dat we bepaalde groepen mensen als aparte groep moeten aanspreken? Wanneer en op wat voor gronden besluiten we dat er sprake is van cultuurverschillen en dat we bijzondere aandacht moeten geven aan culturele diversiteit? En wat hebben we in dit kader aan de psychologie?

\section{Culturele diversiteit in de aidspreventie}

In de praktijk van preventie gaan we voor de bepaling van cultuurverschillen vaak af op grove indicatoren, zoals land van herkomst of etnische achtergrond. Zo ook binnen de aids/soa preventie. Bevolkingsonderzoeken, huisartsenregistraties en gegevens van soapoli's, GGD-en en de Stichting HIV Monitoring geven ons voortdurend informatie over de prevalentie en incidentie van hiv en andere soa (zie 
o.a. De Boer, Op de Coul, Koedijk, Van Veen, Van Sighem \& Van de Laar, 2006; zie ook www.hiv-monitoring.nl). In deze registraties worden gegevens over hiv en soa gekoppeld aan mogelijke gedragsoorzaken, en aan bevolkingskarakteristieken zoals leeftijd, sekse en land van herkomst. Maar kunnen we op basis van dergelijke grove indexen groepen mensen eigenlijk wel onderscheiden naar cultuur?

Wetenschapstheoretisch gezien niet. Statische indexen als land van herkomst en etnische achtergrond doen geen recht aan de complexiteit van cultuur (zie o.a. Bhopal \& Donaldson, 1998). Ze gaan voorbij aan mogelijke cultuurverschillen binnen nationaliteiten of etnische groepen, en nodigen daarbij uit tot stereotypering en discriminatie. Maar met de voeten in de klei zijn dergelijke indexen vaak het enige dat we hebben. Het is lastig om te zien hoe we op voorhand kunnen inschatten of er sprake is van cultuur of cultuurverschillen zonder af te gaan op de grove indelingen als land van herkomst of etnische afkomst. Als we in gezondheidspeilingen fijnmaziger zouden willen gaan, dan zou dit ellenlange vragenlijsten tot gevolg hebben. Dit zou de peilingen onuitvoerbaar maken. Bovendien hoeven we natuurlijk ook niet alles moeilijker te maken dan dat het is. Je hoeft niet gestudeerd te hebben om je te bedenken dat Turken andere software hebben dan Surinamers. Maar als we eenmaal specifieke groepen hebben onderscheiden waarvan we veronderstellen dat ze wel eens een cultuur zouden kunnen delen, dan doen we er vervolgens verstandig aan om nauwkeurig in kaart te brengen of er inderdaad sprake is van gedeelde cultuur, en of, en in welke mate, deze cultuur samenhangt met het gezondheidsprobleem in kwestie (Green \& Kreuter, 2005; Kreuter \& McClure, 2004). Dit geeft ons enerzijds een beter inzicht in waarom mensen zich gedragen zoals zij doen, en het geeft ons anderzijds meer zicht op de mogelijkheden die we hebben om hier met preventieprogramma's verandering in aan te brengen.

Planmatige preventie, Intervention Mapping, biedt in deze kwestie weliswaar geen kant-en-klare oplossing. Het biedt wel een fijnmazige procedure waarin programmamakers voortdurend worden gedwongen om na te denken over of bepaalde groepen mensen een probleem delen, of er sprake is van gemeenschappelijke oorzaken van het probleem, of groepen opvattingen, waarden en gebruiken delen die met het probleem te maken hebben, en of het probleem voor iedereen op een vergelijkbare manier kan worden opgelost. Intervention Mapping garandeert dat programmamakers voortdurend worden uitgedaagd om verder te kijken dan nationaliteit en etnische afkomst, en om in een nauwe samenwerking met hun doelgroepen na te denken over de culturele context van 
problemen, oorzaken en oplossingen.

In ben in dit kader enorm gecharmeerd van het voorstel van Airhihenbuwa (2005) om in het ontwikkelingsproces van preventie een serie workshops op te nemen waarin onderzoekers, preventiewerkers en doelgroepen op systematische wijze consensus proberen te bereiken over de culturele context van gedrag en gezondheid. Wij zijn plan om deze procedure in planmatige preventie op te nemen, en zullen nagaan of we zo meer grip krijgen op het afstemmen van preventie op de volledige culturele ui.

\section{Cultuur, psychologie en aids/soa-preventie}

Het toepassen van theorie over gedrag en gedragsverandering heeft een centrale plaats in de planmatige preventie. Een relevante vraag is hier of de wetenschappelijke theorie die we voorhanden hebben recht doet aan cultuurverschillen?

De psychologie is net als veel andere wetenschappen erg Westers, en vooral erg Amerikaans. Een recente review van alle artikelen die gepubliceerd zijn the Journal of Personality and Social Psychology - een zeer gerenommeerd tijdschrift - laat zien $92 \%$ van de artikelen afkomstig is uit de Verenigde Staten en Canada, en maar liefst 99\% uit Westerse landen (Quinones-Vidal, Lopez-Garcia, Penaranda-Ortega \& Tortosa-Gil, 2004). Als we dan ook nog in ogenschouw nemen dat veel theorievorming binnen de psychologie is gebaseerd op experimenteel onderzoek onder blanke studenten van goede afkomst (Sears, 1986), dan is het niet vreemd dat er mensen zijn die in twijfel trekken of de psychologie bruikbaar is voor mensen uit niet-westerse culturen (Airhihenbuwa \& Obregon, 2000). Een cultuurverschil waar in dit kader vaak naar wordt verwezen, is het onderscheid tussen individualistische en collectivistische samenlevingen of culturen (Hui \& Triandis, 1986; Hofstede \& Hofstede, 2007). Westerse psychologie zou vanwege haar individualistisch perspectief ongeschikt zijn voor culturen waarin de belangen van het individu ondergeschikt zijn aan het belang van de groep, bijvoorbeeld de familie. $U$ kunt hierbij denken aan Aziatische, LatijnsAmerikaanse en Afrikaanse culturen. Culturen waarin het niet zozeer gaat om wat het individu wil of vindt, maar eerder om wat de groep wil of vindt. Hebben we in deze culturen wat aan psychologische theorieën als we gedrag willen verklaren? En wat weten we over de bruikbaarheid van theorie als we gedrag van mensen uit een niet-westerse cultuur willen beïnvloeden? 


\section{Gedragsdeterminanten}

In planmatige preventie maken we bij het analyseren van de factoren die van invloed zijn op ons gedrag - gedragsdeterminanten - vaak gebruik van zogenaamde sociaal-cognitieve theorieën. Eén de meest populaire van deze theorieën is Ajzen's Theorie van Gepland Gedrag (Ajzen, 1991) en haar varianten (De Vries, Dijkstra \& Kuhlman, 1988; Fishbein, 2000).

De Theorie van Gepland Gedrag stelt dat ons gedrag wordt aangestuurd door onze voornemens, onze intenties. Stel dat u vanavond een aantrekkelijk iemand tegen het lijf loopt, en $u$ besluit om een leuke avond een nog veel leuker vervolg te geven. Bent $u$ dan van plan om veilig te vrijen? Dergelijke voornemens zijn volgens de theorie te herleiden tot een drietal factoren: 1) attitudes, 2) sociale invloed, en 3) het vertrouwen dat $u$ hebt om het gedrag in kwestie uit te kunnen voeren, in vaktermen gelabeld met de foeilelijke termen 'eigen-effectiviteit' of gedragscontrole. Attitude is een vakterm voor de afweging van vooren nadelen die aan het gedrag in kwestie kleven. Misschien vind $u$ het gebruiken van condooms maar een irritante onderbreking van een vrijpartij, een onderbreking die bij $u$ alle zin wegneemt. En misschien tilt $\mathrm{u}$ hier zwaarder aan dan aan het voorkomen van mogelijke negatieve gevolgen van onveilige seks. Sociale invloed, het woord zegt het al, staat voor de invloed die anderen direct of indirect op ons gedrag hebben. Misschien vindt uw partner dat $u$ toch vooral veilig moet vrijen wanneer $u$ een scheve schaats wil rijden. Misschien weet $u$ van uw beste vrienden dat zij allen in een vergelijkbare situatie veilig zouden vrijen. En dan is er natuurlijk ook nog degene met wie $u$ in bed belandt. Ook de mate waarin $u$ denkt dat $u$ het gedrag onder controle heeft, is van invloed op uw voornemens. Misschien vindt $u$ het maar gehannes met die condooms, zeker als $u$ wat hebt gedronken. En misschien vindt $u$ het ook wel lastig om over condooms te beginnen. Naarmate we positiever oordelen over gedrag, naarmate we hierin gesteund worden door onze naasten en naarmate we meer het idee hebben dat het ons wel zal lukken, zijn we meer van plan om het gedrag daadwerkelijk uit te voeren. En des te sterker onze voornemens, des te groter de kans dat het ook echt gaat gebeuren. Deze theorie is veelvuldig met succes toegepast bij het analyseren en voorspellen van een breed scala aan gedragingen (Armitage \& Conner, 2001; Godin \& Kok, 1996), waaronder condoom-

gebruik (Albarracín, Johnson, Fishbein \& Muellerleile, 2001; Sheeran, Abraham \& Orbell,1999). De theorie biedt een handzaam raamwerk voor het begrijpen van gedragsintenties, maar ook voor het voorspellen van 
gedrag (zie o.a. Sheeran \& Orbell, 1998).

$\mathrm{Nu}$ denkt $u$ misschien, daar geloof ik helemaal niets van. Ik kan u zeggen, daarin bent $u$ niet de enige. Het model is zo populair dat er voor een wetenschapper niets mooier is dan aan te tonen dat het allemaal niet zo eenvoudig is. Dat er meer onder de zon is dan deze drie factoren (Abraham, Sheeran \& Johnson, 1998). Dat we vaak niet zeggen wat we doen, en niet doen wat we zeggen (Vroon, 1989). Dat ons gedrag vaak ondoorgrondelijk is, en wordt aangestuurd door zaken waar we geen weet van hebben (Aarts, 2006). Dat de theorie te rationeel is, en geen recht doet aan emoties en impulsiviteit, met betrekking tot seks toch geen onbelangrijke factoren (Airhihenbuwa \& Obregon, 2000). En dat het een Westerse, individualistische theorie is.

In een tamelijk ongezouten repliek op deze laatste kritiek stelt Fishbein (2000) dat de theorie met succes is toegepast in veel verschillende landen, en zo $u$ wilt culturen. Met succes, mits de theorie correct wordt toegepast. Ik denk dat Fishbein hier de spijker op zijn kop slaat. Een correct gebruik van de theorie betekent dat elk vragenlijstonderzoek dat aan de hand van de theorie wordt uitgevoerd, alleen betekenisvol kan zijn als het is gebaseerd op een zorgvuldige kwalitatieve analyse van opvattingen, verwachtingen, normen en waarden. Vragenlijstonderzoek kan alleen betekenisvol zijn als het is gebaseerd op een goed begrip van de ideeën van een doelgroep over gedrag en gedragsverandering. Theorieën als de Theorie van Gepland Gedrag bieden een raamwerk van concepten, en bieden methodieken om deze concepten te meten. Maar voor iedere context of doelgroep moet aan deze concepten opnieuw inhoud worden gegeven. Een goed onderzoek naar de redenen van Tanzaniaanse jongeren om zich niet op hiv te laten testen, verzin je niet achter een bureau in Maastricht. Ook vragenlijstonderzoek is onderzoek met de voeten in de klei.

In ons onderzoek in het kader van de preventie van aids en soa hebben wij veel met de Theorie van Gepland Gedrag gewerkt, en ik kan zeggen, met redelijk succes. Ook in onderzoek onder etnische minderheden, en ook in Afrika. Madelief Bertens heeft de theorie met succes toegepast in onderzoek naar de determinanten van het onderhandelen over veilig vrijen door Antilliaanse en Surinaamse vrouwen (Bertens, Schaalma, Wolfers \& Van den Borne, 2007). Uit dit onderzoek blijkt onder meer dat het niet zozeer een gebrek aan zelfvertrouwen is dat vrouwen ervan weerhoudt om safe sex met hun partner te bespreken, maar eerder het feit dat zij de noodzaak er niet zo van inzien. Ons onderzoek onder landarbeiders in Zimbabwe laat zien dat vrouwen weten dat zij risico 
op hiv-infectie lopen, maar dat zij er tegelijkertijd weinig vertrouwen in hebben dat zij er iets aan kunnen doen (Laver, Van den Borne, Kok \& Woelk, 1997). Uit ons onderzoek naar de determinanten van condoomgebruik onder ruim 15.000 jongeren in Zuid Afrika en Tanzania blijkt dat de theorie het net zo goed doet als onder Westerse jongeren en dat voornemens over condoomgebruik net als bij Westerse jongeren sterk worden aangestuurd door attitudes en vermeende gedragscontrole (Schaalma et al., in press). Ons onderzoek loopt daarmee in de pas met internationaal onderzoek (zie o.a. Bryan, Kagee \& Broaddus, 2006; Giles Liddell \& Bydawell, 2005) en steunt het idee dat de theorie, mits goed toegepast, bruikbaar gereedschap is voor het begrijpen van gedrag, ook van mensen met een niet-westerse culturele achtergrond.

De Theorie van Gepland Gedrag mag dan een handig raamwerk zijn, maar waar is cultuur in de theorie? Ik kan u zeggen, die is er niet. Of althans, niet zichtbaar. In de index van het oorspronkelijke werk van Fishbein en Ajzen (1975) vinden we het woord cultuur niet terug. Dat heeft er alles mee te maken dat cultuurverschillen volgens Fishbein en Ajzen zichtbaar zijn in verschillen in attitudes, sociale normen en ideeën over gedragscontrole. Dat zou de theorie juist tot een bruikbaar instrument maken voor het bestuderen van cultuurverschillen. Dit is me echter wat te gemakkelijk.

Ten eerste zeggen verschillen of overeenkomsten in opvattingen niet per definitie iets over cultuur, en is het bijzonder tricky om cultuur af te leiden uit opvattingen. Een mooi voorbeeld is dat de opvattingen van Islamitische meisjes over seks voor het huwelijk sterk overeenkomen met die van streng Protestants Christelijke meisjes. Het verschil tussen hoofddoek en zwarte kous is vaak kleiner dan menigeen denkt, maar er zullen weinig mensen zijn die dit aan een gemeenschappelijke cultuur toeschrijven. Alleen kwalitatief onderzoek of consensus workshops kunnen ons hier verder helpen en ons meer inzicht geven in de relatie tussen opvattingen, gedrag en culturele context. Ik denk dat we er wat dit betreft goed aan zouden doen om de uitkomsten van ons onderzoek eens wat vaker terug te koppelen naar onze doelgroep (Steckler, McLeroy, Goodman, Bird \& McCormick, 1995). Ik denk dat we in onze onderzoeksprocedures veel te weinig gebruik maken van workshops of groepsdiscussies waarin het begrijpen en doorgronden van de uitkomsten van vragenlijstonderzoek centraal staat.

Ten tweede laten verschillende onderzoeken zien dat het toevoegen van indexen voor cultuur kunnen bijdragen aan ons begrip van gedrag en gedragsdeterminanten. Zo laat onderzoek van Paul Kocken zien dat 
sociale normen over veilige seks alleen van invloed zijn op de intenties van mannen met sterk traditionele opvattingen over sekserollen (Kocken, Van Dorst \& Schaalma, 2006). Ik denk dat dergelijk onderzoek waarin sociale cognities worden gekoppeld aan waarden en waardeoriëntaties veelbelovende ontwikkelingen zijn die het verdienen om te worden voortgezet. En dat gaan we dus ook doen.

\section{Gedragsverandering}

Naast theorieën voor het begrijpen en voorspellen van gedrag, heeft de psychologie ook veel te bieden voor het veranderen van gedrag en gedragsdeterminanten. De psychologie biedt een groot warenhuis vol met theorieën over onder andere risicocommunicatie, attitudeverandering, het verhogen van zelfvertrouwen, het aanleren van vaardigheden, en over hoe we kunnen bevorderen dat gedragsverandering beklijft (Glanz, Rimer \& Lewis, 2002; Bartholomew et al., 2006). Dat is mooi, al die theorie, maar tegelijkertijd erg vervelend. De psychologie biedt jammer genoeg geen theorie die te allen tijde, voor ieder probleem, iedere situatie en iedere doelgroep bruikbaar is. Dit betekent dat programmaontwikkelaars zich telkens weer moeten afvragen of een bepaalde theorie bruikbaar is om de gewenste veranderingen te bewerkstelligen.

Bij het beoordelen van de bruikbaarheid van een theorie, kunnen we als het mee zit afgaan op de zogenaamde parameters van een theorie: specificaties van de condities waaronder een theorie bruikbaar is of niet. Een van die parameters of condities zou cultuur of waardeoriëntatie kunnen zijn. Maar daar zit hem nu juist de kneep, want we weten bijzonder weinig van de bruikbaarheid van psychologische theorieën in niet-westerse culturen. We weten bijzonder weinig over de invloed van waardeoriëntaties op de bruikbaarheid van onze theorieën.

De crossculturele psychologie geeft ons echter wel aanwijzingen dat we er niet zonder meer van uit kunnen gaan dat psychologische processen en mechanismen universeel zijn (zie voor een overzicht: Matsumoto \& Juang, 2004). Zo blijkt dat mensen in Westerse landen hun zelfbeeld aan andere zaken ontlenen dan mensen in Aziatische landen (Singelis, Bonk, Sharkey \& Siu Yiu Pai, 1999), en dat er ook culturele verschillen zijn in de manier waarop mensen een positief zelfbeeld proberen te handhaven (Heine, Kitayama \& Lehman, 2001). Zo suggereert onderzoek dat mensen in individualistische culturen extra gemotiveerd raken door succeservaringen, terwijl mensen in collectivistische samenlevingen er juist na faalervaringen een schepje bovenop doen (Heine, Lehman et al., 2001). Ook lijken er culturele verschillen te bestaan in de neiging die we 
hebben om onszelf en onze prestaties met anderen te vergelijken (White \& Lehman, 2005).

Het voert hier te ver om een volledig overzicht te geven van de crossculturele psychologie. Maar ik denk dat we wel kunnen stellen dat psychologische processen niet per definitie universeel zijn, en dat cultuur van invloed kan zijn op de wijze waarop psychologische processen tot uiting komen. Dit onderstreept eens te meer dat het belangrijk is dat programmamakers zich voortdurend blijven afvragen of en hoe zij een theorie kunnen gebruiken voor hun preventieprogramma. Een verdergaande integratie van planmatige preventie en inzichten uit de crossculturele psychologie lijkt hierbij wat te helpen, zij het dat de crossculturele psychologie wordt overheerst door onderzoek waarin Amerikanen worden vergeleken met Aziaten, en dat Afrika weer eens niet of nauwelijks meedoet.

Het gaat me te ver om hier te roepen dat wij hier verandering in gaan aanbrengen. Maar ik kan u wel zeggen dat ik samen met Rob Ruiter en onderzoekers van de Universiteit van Kaapstad bezig ben met het opzetten van een onderzoekslijn in de experimentele psychologie. We willen ons vooral richten op het testen van psychologische theorieën die van belang kunnen zijn voor de aidspreventie. Het gaat ons hierbij niet om het in kaart brengen van verschillen tussen Zuid Afrikanen en Nederlanders. We zijn meer geïnteresseerd in de vraag 'hoe' en onder welke condities psychologische processen in een Zuid-Afrikaanse context verlopen.

\section{Aidspreventie aan migranten in Nederland}

Ik ben gaandeweg begonnen om u wat te vertellen over projecten en onderzoeken die we in het verleden hebben uitgevoerd, over onze plannen voor de toekomst. En het is zo langzamerhand tijd dat ik me daarop toespits.

In Nederland zijn er in totaal circa 12.000 mensen met hiv geregistreerd; ruim 9.000 mannen en een kleine 3.000 vrouwen. Naast mannen die seks hebben met andere mannen zijn niet-westerse migranten een belangrijke risicogroep: $43 \%$ van de mensen met hiv is niet in Nederland geboren. Het betreft hier vooral mensen uit zwart Afrika (41\%), en mensen uit Latijns Amerika en de Cariben (25\%) (De Boer et al., 2007). De meeste van deze mensen zijn geïnfecteerd door heteroseksueel contact, al verschilt dit per migrantengroep. Voor zover we het 
weten, hebben de meeste Afrikanen hiv opgelopen in Afrika, en zijn de meeste Surinamers, Antillianen, Turken en Marokkanen in Nederland besmet. Maar ook dat verschilt weer per groep; zo is een meerderheid van de heteroseksuele Antillianen op de Antillen besmet geraakt. Naast deze hiv cijfers zien we dat sommige migrantengroepen zijn oververtegenwoordigd bij de soa-diagnosen (Van Bergen et al., 2005). Ook zien we onder migranten uit landen waar hiv relatief veel voor komt veel seksueel risicogedrag (zie o.a. Gras, Weide, Langendam, Coutinho \& Van den Hoek, 1999; Van Veen et al., 2005): veel partners, gelijktijdige partners, weinig condoomgebruik en onbeschermde seks met losse partners in het land van herkomst. En allemaal vooral bij mannen. Nederland is wat dit betreft trouwens niet uniek; in andere Europese landen zien we vergelijkbare trends (Hamers \& Downs, 2006).

Voor migrantengroepen is er de afgelopen jaren een breed scala aan preventieprogramma's ontwikkeld. Wat weten we nu van de mate waarin deze programma's cultuursensitief, planmatig en effectief zijn?

In samenwerking het onderzoeksbureau ResCon hebben wij vorig jaar een onderzoek uitgevoerd naar de kwaliteit van de hiv/soa preventie voor migrantengroepen in Nederland (Vrolings, Gelissen, Jonkers \& Schaalma, 2006). We hebben experts een inventarisatie laten maken van de beste preventieprojecten, en deze projecten hebben we vervolgens langs een meetlat voor planmatige preventie gelegd. Aan de hand van documenten en interviews hebben we geprobeerd om te achterhalen of programmadoelen empirisch waren onderbouwd, of preventieactiviteiten waren gebaseerd op een theoretisch idee, of de doelgroep bij de ontwikkeling was betrokken, en of programma's waren uitgetest en geëvalueerd. De conclusies van dit onderzoek zijn drieledig. Allereerst moeten we concluderen dat de planmatigheid van veel projecten te wensen over laat, vooral wat betreft de theoretische fundering en programma-evaluatie. Voor preventieprogramma's die zijn gebaseerd op een samenwerking tussen praktijk en universiteit, is de situatie doorgaans beter. We kunnen ook concluderen dat er bij alle projecten flink is geïnvesteerd in culturele sensitiviteit, vooral door mensen uit de doelgroep actief te betrekken bij de ontwikkeling en uitvoering van de programma's. En dat is natuurlijk een verheugende constatering, al moeten we hierbij de kanttekening plaatsen dat het bij culturele sensitiviteit vaak vooral gaat om strategieën die zijn gericht op de schil van de culturele ui. Over de afstemming van programma's op het hart van de culturele ui kunnen we weinig zeggen. En dat brengt mij bij de laatste conclusie. Op enkele uitzonderingen na laat de docu- 
mentatie van het ontwikkelingsproces bij veel programma's veel ruimte voor verbetering. I $\mathrm{k}$ heb al eerder gewezen op het belang van goede programmabeschrijvingen, maar ik wil nogmaals benadrukken dat het ook de preventiepraktijk enorm ten goede zou komen als we beter documenteren wat we doen, hoe we het doen, wanneer we het doen, met wie we het doen, en hoe vaak we het doen. We zullen hier de komende jaren op blijven hameren.

In de loop der jaren is er een nauwe samenwerking ontstaan tussen de Universiteit Maastricht en de GGD Rotterdam Rijnmond. Als ik mij beperk tot aidspreventie, dan is dat ooit begonnen met een betrokkenheid bij aidsvoorlichting in Turkse koffiehuizen (Kocken, Voorham, Brandsma \& Swart, 2001), en Amor i Salú, een community-project over seksuele gezondheid voor Antillianen (Kocken, Wouter, Voorham \& De Zwart, 2003). De samenwerking met de groep van Onno de Zwart is geïntensiveerd in het Uma Tori!-project van Madelief Bertens, een planmatig aidspreventieproject voor Antilliaanse, Arubaanse en Surinaamse vrouwen (Bertens et al., 2004). Een project dat heeft geresulteerd in een voorlichtingprogramma waarin groepen vrouwen onder begeleiding van een gastvrouw en voorlichtster in een vijftal groepsbijeenkomsten worden gemotiveerd om stil te staan bij hun seksualiteit, hun relaties en seksuele risico's, en om met elkaar oplossingen te zoeken voor eventuele problemen. Een programma dat door de vrouwen en de voorlichtsters goed is ontvangen, en waarvan de voorlopige analyses wijzen op goede resultaten.

De samenwerking met Rotterdam wordt gecontinueerd in een project van Mireille Wolfers dat erop is gericht om studenten van regionale opleidingscentra, waaronder erg veel migranten, aan te zetten om zich op soa te laten testen. Daarnaast werken we samen met Paul Harterink en Pjer Vriens aan de ontwikkeling van een web-based aids/soa preventieprogramma voor jongeren, een project dat ons de mogelijkheid geeft om te experimenteren met interactieve computergestuurde voorlichting waarin voorlichtingsboodschappen individueel kunnen worden afgestemd op opvattingen, waarden en gedrag: culturele sensitiviteit op individueel niveau.

Naast al dit onderzoek zijn Sarah Stutterheim en Arjan Bos sinds enkele maanden in samenwerking met de HIV Vereniging en Soa Aids Nederland hard aan het werk om meer zicht te krijgen op stigmatisering en discriminatie die door mensen met hiv wordt ervaren, onderzoek dat zal uitmonden in richtlijnen en doelstellingen voor toekomstige interventies om stigmatisering tegen te gaan. 
In al deze projecten volgen we de systematiek van planmatige preventie. Dit biedt ons de mogelijkheid om te werken aan een verdere uitwerking van onderzoeks- en ontwikkelingsprocedures die ten goede komen aan het bewerkstelligen van cultuursensitieve aidspreventie.

\section{Aidspreventie in Afrika}

Tot nu toe heb ik een aspect van culturele sensitiviteit buiten beschouwing gelaten: culturele competentie, de vaardigheid of bereidwilligheid om open te staan voor cultuurverschillen.

Terwijl ik dit opschreef, moest ik terugdenken aan een vergadering, ergens in 1997 in een kantoor van de Europese Commissie in Brussel. Gespeend van enige culturele competentie was ik terechtgekomen in een vergadering met West-Afrikanen die verantwoordelijk waren voor de uitvoering van een aidspreventieprogramma. Nog nooit heb ik mij zo geërgerd aan het verloop van een vergadering, en vooral aan de Duitse voorzitter. Ik vond het één grote ongestructureerde bende waarin iedereen ongeacht het agendapunt dat aan de orde was, zijn of haar zegje kon doen, en waarin niemand naar elkaar leek te luisteren. Na afloop bleek echter dat ik de enige was die zich had zitten ergeren. ledereen was erg ingenomen met het verloop van de vergadering, en vooral met de voorzitter omdat hij hen de gelegenheid hadden gegeven om te kunnen zeggen wat ze op hun lever hadden. Inmiddels weet ik beter, denk ik. En ik kan u zeggen dat de Maastrichtse mentaliteit mij daarbij goed heeft geholpen. Het gaat zoals het gaat.

Ons werk in Afrika concerteert zich vooral op het ondersteunen van organisaties in Zuid Afrika en Tanzania. Bart van den Borne en Rob Ruiter ondersteunen al jaren de Medical Research Council in Kaapstad, en hebben onder andere bijgedragen aan de aidspreventie in soa-klinieken (Reddy \& Meyer-Weitz, 1999) en gevangenissen (Sifunda, 2006).

Verder waren wij de afgelopen jaren betrokken bij een project dat was gericht op de ontwikkeling van lesprogramma's voor scholieren (Aarø et al., 2005). Onze bijdrage bestond uit het ondersteunen van onderzoekers en programmaontwikkelaars bij het toepassen van Intervention Mapping, een taak die wij samen met Joanne Leerlooijer en Jo Reinders van World Population Foundation hebben uitgevoerd.

Dit heeft uiteindelijk drie lesprogramma's opgeleverd die alle redelijk doortimmerd zijn, die tot op zekere hoogte in samenwerking met jongeren en docenten zijn ontwikkeld, en waarin naast aandacht voor hiv/ aids en andere ellende ook enkele leuke kanten van seksualiteit aan bod 
komen. De evaluatie van deze programma's is nog niet volledig afgerond maar voor zover het zich laat aanzien, hebben de programma's weinig effect gehad op het seksuele gedrag van de jongeren. Teleurstellende resultaten, die eens te meer duidelijk maken dat deze jongeren van ver moeten komen waar het gaat om de preventie van aids. En dat we in Afrika veel meer uit de kast moeten halen dan een lespakket om veilige seks te bevorderen.

Een ander project waar wij sinds enkele jaren bij betrokken zijn, is gericht op onderzoek en capacity building in het kader van de bestrijding van zogenaamde poverty related infectious diseases in Tanzania en Indonesië: malaria, tuberculose en hiv/aids. Ook in dit project, PRIOR, bestaat onze bijdrage uit het ondersteunen van lokale onderzoekers bij het opzetten en uitvoeren van sociaal-wetenschappelijk onderzoek en bij het ontwikkelen van preventie. Harm Hospers richt zich op aidspreventie onder druggebruikers in Indonesië. Met hulp van Marijn de Bruin werk ik aan het bevorderen van hiv testen en therapietrouw in Tanzania.

Ik denk dat deze projecten illustratief zijn voor de manier waarop wij samenwerken met organisaties in ontwikkelingslanden. We proberen mensen te scholen en te ondersteunen bij het uitvoeren van planmatige preventie, opdat zij zelf problemen en oorzaken kunnen analyseren, en zelf op zoek kunnen gaan naar mogelijke oplossingen. We geven ze geen vis, en zelfs geen hengel. Maar we proberen ze te ondersteunen bij het opzetten van een hengelfabriek.

\section{Tot slot}

Ik ben zo langzamerhand aan het einde van mijn rede gekomen. Ik heb $u$ duidelijk proberen te maken dat cultuursensitieve aidspreventie geen sinecure is, en dat er zowel vanuit wetenschappelijk als vanuit praktisch oogpunt nog het nodige werk te doen is. Ik heb een systematiek van planmatige preventie geschetst die het ons daarbij wat gemakkelijker moet maken, maar ik heb tevens laten zien dat er nog wel wat losse eindjes zijn. En ik heb u een overzicht gegeven van waar wij ons zoal mee bezig houden, en welke plannen we hebben voor de toekomst. Ik had $\mathrm{u}$ natuurlijk veel meer willen vertellen. Over ons onderwijs over aidspreventie, over de verschillende kleine onderzoeksprojecten naar aids-gerelateerd stigma in Afrika, over een project dat ik samen met Liesbeth Rijsdijk en Arjan Bos aan het opstarten ben in het kader van de preventie van stigmatisering in de Cariben, over onze wilde plannen om kerken en moskeeën bij aidspreventie te betrekken, over de samenwer- 
king met World Population Foundation in het uitdragen van planmatige preventie in ontwikkelingslanden en over plannen voor aidspreventie onder migranten in Bangla Desh. Ook had ik u willen inlichten over onze pogingen om geld te krijgen voor een project om hetero migrantenmannen bij de aidspreventie te betrekken. Maar ik vind het wel welletjes geweest, en ik heb zowaar voor het eerst van mijn leven zin in een receptie.

\section{Dankwoord}

Dames en heren, voordat we iets gaan drinken wil ik afsluiten met het bedanken van een aantal mensen die op de een of andere manier hebben bijgedragen aan het feit dat ik $u$ hier wat heb mogen vertellen.

Een eerste woord van dank is voor het bestuur van het Aidsfonds, het College van Bestuur en het college van Dekanen van de Universiteit Maastricht, en het bestuur van de Faculteit der Psychologie. Ik dank u allen voor het continueren van de leerstoel Aidspreventie in Maastricht en voor uw vertrouwen dat ik er wat moois van ga maken. Ik kan u zeggen: met mijn voornemens zit het wel goed.

Een tweede woord van dank gaat uit naar twee wijze heren. Allereerst was er Charles Vlek die de euvele moed had om mij als onderzoeker aan te stellen op een moment dat ik op het punt stond de wetenschap aan de wilgen te hangen. Beste Charles, jouw bevlogenheid en maatschappelijke betrokkenheid heeft bij mij een kwartje doen laten vallen en heeft me destijds het plezier in de wetenschap teruggegeven. Ik stel het erg op prijs dat je hier vandaag bent.

Dan is er Gerjo Kok, onze hooggeleerde officier. Het begon allemaal met een cursus over attitudeverandering, ergens in het begin van de jaren 80. Jij was toen nog in de ban van de ring en de PSP, en opmerkelijk mild als er in je omgeving werd gerookt. Ik had toen nog haar tot op mijn schouders en was zeker 20 kilo lichter. Sindsdien fiets ik eigenlijk wat achter je aan. Je hebt me een paar keer flink los gereden, daar kon geen doping tegen op, maar steeds weer kruisen zich onze wegen. De laatste tijd geef je me heel af en toe het idee dat ik jouw wiel kan houden, maar ik ben er eigenlijk al jaren van overtuigd dat jouw fiets gewoon veel harder kan dan die van mij. Jou opvolgen als hoogleraar Aidspreventie is natuurlijk het domste dat iemand kan doen, maar ik prijs me gelukkig dat ik nog een tijd beroep op je kan blijven doen op je kwaliteiten als wegkapitein en soigneur.

Werken aan aidspreventie is niet alleen inspirerend vanwege het 
maatschappelijke belang, maar ook zeker vanwege de leuke mensen die in dit veld werken. Zo zijn er in Maastricht de collega's van RESHAPE en de vakgroep Toegepaste Sociale Psychologie, en op wat meer afstand de collega's van de Faculteit der Psychologie. Zo zijn er in het land de mensen bij Soa Aids Nederland, de GGD Rotterdam Rijnmond en World Population Foundation. Dames en heren, jongens en meisjes, zonder jullie zou ik hier niet staan. Ik fiets iedere dag vrolijk naar mijn werk, en de vergaderingen en bijeenkomsten in het Westen maken de treinreizen meestal meer dan goed.

Met het gevaar om een aantal mensen te kort te doen, wil ik er toch een paar uitlichten. Louk Peters en Henk Aarts, de vieze jongens van GVO. Het jaar dat wij op de Kapoenstraat hebben zitten geiten, was een van mijn leukste en meest succesvolle jaren als onderzoeker. Dat heb ik toch maar mooi mede aan jullie te danken.

Een speciaal woord van dank heb ik ook voor Jos Poelman, met wie ik al jaren met erg veel plezier samenwerk aan aids/soa-preventie voor jongeren. Hetzelfde geldt voor Jo Reinders, wiens werk met Intervention Mapping in ontwikkelingslanden ik enorm bewonder. Jo, ik droom nog vaak van de workshops die wij samen met Joanne Leerlooijer in Afrika hebben gehouden. En ondanks dat ik dan badend in het zweet wakker schrik, hoop ik dat we het allemaal nog eens een keer over kunnen doen.

Eén man verdient een extra woord van dank. Harm, mijn TomTom voor de wondere universitaire wereld in Maastricht, mijn steun en toeverlaat in alles wat met regels, procedures en verzekeringen heeft te maken. Voor iemand die alles beter weet, zoals ik, is het mooi om iemand te kennen die alles nog veel beter weet. lemand die mij gevraagd en meestal ongevraagd uitlegt hoe de wereld in elkaar zit, en die glimlachend zucht als ik alle goed raad weer eens naast me heb gelegd, of alles domweg ben vergeten. Harm, ga vooral zo door.

Nora. Toen je erachter kwam dat ik een student was, was dit niet in mijn voordeel. Net zo min als dat het in mijn voordeel is dat ik hier volgens jou in een pekske sta waarmee ik op 5 december geen slecht figuur zou slaan. Noor, als er een is die mij met de voeten in de klei houdt, dan ben jij het. Zonder jou is het allemaal drie keer niks.

Ik heb gezegd. 


\section{Referenties}

Aarø, L.E., Flisher, A.J., Kaaya, S., Onya, H., Fuglesang, M., Klepp, K.-I., \& Schaalma, H. (2005). Promoting sexual- and reproductive health in early adolescence in South Africa and Tanzania: Development of a theory- and evidence-based intervention programme. Scandinavian Journal of Public Health, 30, 148-160.

Aarts, H. (2006). Onbewust doelgericht gedrag en de corrosie van de ijzeren wil. Utrecht: Universiteit Utrecht.

Abraham, C., Sheeran, P., \& Johnson, M. (1998). From health beliefs to self-regulation: theoretical advances in the psychology of action control. Psychology and Health, 13. 569-591.

Ajzen, I. (1991). The theory of planned behavior. Organizational Behavior and Human Decision Processes, 50, 179-211.

Airhihenbuwa, C.O. (1995). Health and Culture: Beyond the Western Paradigm. Sage Publications, Thousand Oaks, California.

Airhihenbuwa, C.O. (2005). Healing Our Differences: The Crisis of Global Health And the Politics of Identity. Lanham MD: Rowman \& Littlefield Publishers

Airhihenbuwa C.O., \& Obregon R. (2000). A critical assessment of theories/models used in health communication for HIV/AIDS. Journal of Health Communication, 5 Suppl, 5-15.

Albarracín, D., Johnson, B.T., Fishbein, M., \& Muellerleile, P.A. (2001). Theories of reasoned action and planned behavior as models of condom use: A meta-analysis. Psychological Bulletin, 127, 142-161.

Armitage, C., \& Conner, M. (2001). Efficacy of the Theory of Planned Behaviour: A meta-analytic review. British Journal of Social Psychology, 40, 471-499

Bandura, A. (2002). Social Cognitive Theory in Cultural Context. Applied Psychology: An International Review, 51, 269-290.

Bartholomew, L. K., Parcel, G. S., Kok, G., \& Gottlieb, N. H. (2006). Planning health promotion program. An intervention mapping approach (2nd edition). San Francisco: Jossey-Bass. 
Bernal, G., Bonilla, J., \& Bellido, C. (1995). Ecological validity and cultural sensitivity for outcome research: Issues for the cultural adaptation and development of psychosocial treatments with Hispanics. Journal of Abnormal Child Psychology, $23,67-82$.

Bertens, M.G.B.C., Schaalma, H.P., \& Van den Borne, B. (2004). Risk awareness, goal setting, self-esteem and communication: Factors influencing safe sex and implications for interventions aimed at Dutch Caribbean women. Migrant Health in Europe. International conference on differences in health care provision, Rotterdam. Ethnicity and Health, 9, S48-S49.

Bertens, M.G.B.C., Wolfers, M.E.G., Van den Borne, B., \& Schaalma, H.P. (manuscript under review). Negotiated safety and condom use among women of AfroSurinamese and Dutch Antillean descent in the Netherlands.

Bryan, A., Kagee, A., \& Broaddus, M.R. (2006). Condom Use among South African Adolescents: Developing and Testing Theoretical Models of Intentions and Behavior. AIDS and Behavior, 10, 387-397.

De Boer, I.M., Op de Coul, E.L.M., Koedijk, F.D.H., Van Veen, M.G., Van Sighem, A.L., \& Van de Laar, M.J.W. (2006). HIV and Sexually Transmitted Infections in the Netherlands in 2005. RIVM report 441100024. Bilthoven: RIVM.

De Vries, H., Dijkstra, M., \& Kuhlman, P. (1988). Self-efficacy: The third factor besides attitude and subjective norm as predictor of behavioral intentions. Health Education Research, 3, 273-282.

Fishbein, M. (2000). The role of theory in developing HIV prevention programs. AIDS Care, 12, 273-278.

Fishbein, M., \& Ajzen, I. (1975). Belief, attitude, intention, and behavior. New York: Wiley.

Giles, M., Liddell, C., \& Bydawell, M. (2005). Condom use in African adolescents: the role of individual and group factors. AIDS Care, 17, 729-739.

Glanz, K., Rimer, B.K., \&. Lewis, F.M. (2002). Health behavior and health education: theory, research and practice (3rd edition). San Francisco: Jossey-Bass 
Godin, G., \& Kok, G. (1996). The theory of planned behavior: A review of its applications to health-related behaviors. American Journal of Health Promotion, 11, 87-98.

Gras, M.J., Weide, J.F., Langendam, M.W., Coutinho, R.A., \& Van den Hoek, A. (1999). HIV prevalence, sexual risk behaviour and sexual mixing patterns among migrants in Amsterdam, the Netherlands. Journal of Acquired Immune Deficiency Syndromes, 13, 1953-1962.

Green, L.W., \& Kreuter, M.W. (2005). Health program planning: an educational and ecological approach. New York: McGraw-Hill

Groseschl, S., \& Doherty, L. (2000). Conceptualising culture. Cross Cultural Management, 7, 12-17.

Hamers, F, \& Downs, A. (2006). The changing face of the HIV epidemic in Western Europe: what are the implications for public health policies? The Lancet, 364 , 83-94.

Heine, S.J., Kitayama, S., \& Lehman, D.R. (2001). Cultural Differences in SelfEvaluation. Japanese Readily Accept Negative Self-Relevant Information. Journal of Cross-Cultural Psychology, 32, 434-443.

Heine, S.J., Lehman, D.R., Die, E., Leung, C., Kitayama, S., Takata, T., \& Matsumoto, H. (2001). Divergent consequences of success and failure in Japan and North America: an investigation of self-improving motivations and malleable selves. Journal of Personality and Social Psychology, 81, 599-615.

Hofstede, G., \& Hofstede, G.J. (2007) Allemaal anders-denkenden. Omgaan met cultuurverschillen. Amsterdam: Uitgeverij Contact.

Hui, C.H., \& Triandis, H.C. (1986). Individualism-Collectivism A Study of CrossCultural Researchers Journal of Cross-Cultural Psychology, 17, 225-248.

Kocken, P.L., Van Dorst, A., \& Schaalma, H. (2006).The contribution of cultural factors at determinants of condom use intention in immigrants from the Netherlands Antilles. Health Education Research, 21, 230-238. 
Kocken, P., Voorham, T., Brandsma, J., \& Swart, W. (2001). Effects of peer-led AIDS education aimed at Turkish and Moroccan male immigrants in the Netherlands: a randomized controlled evaluation study. The European Journal of Public Health 11, 153-159.

Kocken, P., Wouter, L., Voorham, T., \& De Zwart, O. (2003). Amor i salu: het Rotterdamse communityproject ter bevordering van de seksuele gezondheid van Antillianen en Arubanen. Rotterdam: GGD Rotterdam.

Kok, G. , Schaalma, H., \& Brug, J. (2007). Planmatige bevordering van gezond gedrag. In: J. Brug, P. van Assema \& L. Lechner (red.). Gezondheidsvoorlichting en gedragsverandering (pp. 15-32). Assen: Van Gorcum.

Kreuter, M., Lukwago, S., Bucholtz, D., Clark, E., \& Sanders-Thompson, V. (2003) Achieving cultural appropriateness in health promotion programs: Targeted and tailored approaches. Health Education \& Behavior, 30, 133-146.

Kreuter, M.W., \& McClure, S.M. (2004). The role of culture in health communication. Annual Review of Public Health, 25, 439-455.

Laver, S.M., van den Borne, B., Kok, G., \& Woelk, G. (1997) A pre-intervention survey to determine understanding of HIV and AIDS in farm worker communities in Zimbabwe. Aids Education \& Prevention, 9, 94-110.

Matsumoto, D., \& Juang, L. (2004). Culture and Psychology. Belmont, Wadsworth/ Thomson

Quinones-Vidal, E., Lopez-Garcia, J.J., Penaranda-Ortega, M., \& Tortosa-Gil, F. (2004). The nature of social and personality psychology as reflected in JPSP, 1965-2000. Journal of Personality and Social Psychology, 86, 435-452.

Reddy, P., \& Meyer-Weitz, A. (1999). Sense \& Seinsibilities. The psychosocial and contextual determinants of STD-related behaviors. Tygerberg: Medical Research Council.

Resnicow, K., Baranowski, T., Ahluwalia, J.S., \& Braithwaite, R.L. (1999). Cultural sensitivity in public health: defined and demystified. Ethnicity \& Disease, 9, 10-21. 
Schaalma, H., \& Kok, G. (2006). A School HIV-Prevention Program in the Netherlands. In: L.K. Bartholomew, G.S. Parcel, G. Kok, \& N.H. Gottlieb (Eds). Planning Health Promotion Programs: An Intervention Mapping Approach (pp. 511-544). San Francisco, CA: Jossey-Bas.

Schaalma, H., Aarø, L., Flisher, A., Kaaya, S., Mathews, C., Onya, H., Ragnarson A., \& Klepp, K-I. (in press). Schaalma, Condom use among SSA youth: A test of the applicability of an extended version of the Theory of Planned Behaviour to model psychosocial correlates of condom use in African contexts. Scandinavian Journal of Public Health.

Sears, D.O. (1986). College Sophomores in the Laboratory: Influences of a Narrow Data Base on Social Psychology's View of Human Nature. Journal of Personality and Social Psychology, 51, 515-535.

Sheeran, P., \& Orbell, S. (1998) Do intentions predict condom use? A meta-analysis and examination of six moderator variables. British Journal of Social Psychology, 37, 231-250.

Sheeran, P., Orbell, S., \& Abraham, C. (1999) Psycholsocial correlates of heterosexual condom use: a meta-analysis. Psychological Bulletin, 1, 90-132.

Sifunda, S. (2006). Ubudoda Abukhulelwa. The development and testing of a peerled STI, HIV and AIDS prevention intervention for male prison inmates in South Africa. Tygerberg: Medical Research Council.

Singelis, T.M., Bond, M.H., Sharkey, W.F., \& Siu Yiu Lai, C. (1999). Unpackaging Culture's Influence on Self-Esteem and Embarrassability. The Role of SelfConstruals. Journal of Cross-Cultural Psychology, 30, 315-341.

Steckler, A., McLeroy, K.R., Goodman, R.M., Bird, S.T., \& McCormick, L. (1992). Toward Integrating Qualitative and Quantitative Methods: An Introduction. Health Education Quarterly, 19:1-8.

Stolte, I.G., Gras, M., Van Benthem, B.H., Coutinho, R.A., \& Van den Hoek, J.A. (2003). HIV testing behaviour among heterosexual migrants in Amsterdam. AIDS Care, $15,563-574$. 
Van Bergen, J.E.A.M., Kerssens, J.J., Schellevis, F.G., Sandfort, T.G., Coenen, T.J. \& Bindels, P.J. (2005). Prevalence of STI related consultations in general practice: results from the second Dutch National Survey of General Practice. British Journal of General Practice, 56: 104-109.

Van Veen, M.G., Beuker, R.J., De Brito. O., Götz, De Koster, M., Al Taqatqa, W., De Zwart, O., \& Van de Laar, M.J.W. (2005). HIV-surveys bij hoog-risicogroepen Rotterdam 2002-2003. RIVM rapport 441100019. Bilthoven: RIVM

Vrolings, E., Gelissen, R., Jonkers, R., \& Schaalma, H. (2006). SOA en HIV/AIDS-preventie onder etnische minderheden in Nederland. Amsterdam: Soa Aids Nederland.

Vroon, P. (1989). De tranen van de krokodil. Baarn: Ambo

White, K., \& Lehman, D.L. (2005). Culture and Social Comparison Seeking: The Role of Self-Motives. Personality and Social Psychology Bulletin, 31, 232-242.

Wilson, B.D.M., \& Miller, R.L. (2003). Examining Strategies for Culturally Grounded HIV Prevention: A Review. AIDS Education and Prevention, 15, 184-202. 